\title{
Pre-Adoption of KMS: User Acceptance from Knowledge Worker Perspectives
}

\author{
Setiawan Assegaff \\ Program Pasca Sarjana \\ Magister Sistem Informasi \\ STIKOM Dinamika Bangsa \\ Jambi, Indonesia \\ E-mail: asetiawan2@live.utm.my
}

\author{
Ab Razak Che Hussin \\ Faculty of Computer and \\ Information System \\ Universiti Teknologi Malaysia \\ Johor, Malaysia \\ E-mail: abrazak@utm.my
}

\author{
Halina Mohamed Dahlan \\ Faculty of Computer and \\ Information System \\ Universiti Teknologi Malaysia \\ Johor, Malaysia \\ E-mail: halina@utm.my
}

\begin{abstract}
Non-technological problem has been identified as main barriers in knowledge management implementation. Culture and people have been identified as main barriers. Lack of understanding the benefit of using knowledge management system (KMS) makes people unaware about KMS. There are two types of knowledge workers which have different belief in KMS benefit. Benefit from the knowledge seekers perspective will be different with knowledge contributors. Current KMS acceptance model focus in evaluate and understand the user acceptance from knowledge seeker perspective. There is a lack of models that can be used to evaluate and understand user from both knowledge seeker and contributor perspective. Thus, this study proposes a modified model to understand both knowledge worker acceptances of KMS.
\end{abstract}

Keywords - Knowledge Management, KMS, Technology Adoption, Knowledge Workers.

\section{INTRODUCTION}

$I^{\prime}$ n order to implement effective knowledge management (KM), an organization needs to consider developing KMS. KMS is an IT system to support KM activities in an organization. A survey conducted by KPMG in 2001 revealed that most of organization in Europe and United States interested to adopt and implement KMS in their organization. In addition only 7 percent of that companies mention that technology as a barrier to successful implementation of KM. KMS by nature is IT-base system, but there is a unique issue about KMS make its different with others Information System.

Problems related with people or employee have been identified as main barriers in KMS implementation such as, employee don't have enough time to share their knowledge, they don't feel will get benefit from doing so, and employee afraid to share their knowledge, because they believed their knowledge is their personal competitive advantages. If the employee did not want to share their knowledge it means they would not use KMS as tools for knowledge sharing. When the employee did not have intention to use KMS, the mission of KMS to support leverage knowledge would fail.
User would use KMS if they are willing to share or want to seek knowledge. Furthermore they also will not use KMS if did not get benefit from it. Employee in organizations is main actors in knowledge sharing. KS is a key component of KMS [1].

There are two actors in KM initiative knowledge seeker (people who consider using or reuse knowledge) and knowledge contributor (people who contribute knowledge). Benefit gains from knowledge seeker perspective will be different with knowledge contributor.

Existing KMS model has limitation in understand different belief from knowledge workers. The model use general perspective in understand knowledge workers. There is a need of a model that can use to explain different factors influence seeker and contributor in acceptance KMS which lead organization develop effective intervention in KMS acceptance success. This paper will fill that gap.

This paper consists of seventh sections. In section two KM, and KMS will be defined and the state-of-art of $\mathrm{KM}, \mathrm{KS}$ and KMS, KMS acceptance research will be discussed. Section three explains about discussion in past research in $\mathrm{KS}$, the limitation, and potential research can be done. Section four will explain our propose solution in KMS acceptance research limitation. Section Five discusses how TAM can be used to understand KS activities through KMS. Section Six explains how TAM is adapted in KMS acceptance. The last sections propose a recommendation solution in KS and KMS problem, and highlight some further works of the research.

\section{LITERATURE REVIEW}

\section{A. Knowledge Management}

$\mathrm{KM}$ initiative is about approaches and programs that company is undertaking to achieve the $\mathrm{KM}$ mission in their organization. Knowledge management refers to changing corporate culture and business procedures to make sharing of information possible. Knowledge worker as part of an organization are the key source of knowledge acquired and manage by KMS. 


\section{B. Knowledge Sharing}

Berthold \& Srivastava defined KS as individuals sharing organizationally relevant information, ideas, suggestions, and expertise with one another [2]. In this paper we use definition of knowledge sharing from Kurkarni [11] KS to mean both contributing and using available knowledge.

TABLE I

FACTORS CONTRIBUTE IN KS FROM ORGANIZATIONAL CONTEXT

\begin{tabular}{|c|c|c|}
\hline Focus & Researcher & Result \\
\hline $\begin{array}{l}\text { Organization Culture } \\
\text { and Climate }\end{array}$ & $\begin{array}{l}\text { De long and Fahey } \\
\text { (2000) } \\
\text { Kankanhali, Tan, Wei } \\
\text { (2005); Chiu, Hsu, \& } \\
\text { Wang (2006) } \\
\text { Ruppel \& Harrington } \\
\text { (2001) }\end{array}$ & $\begin{array}{l}\text { The Benefits of new technology infrastructure } \\
\text { were limited if long-standing organization values } \\
\text { and practicas were not supportive of knowledge } \\
\text { sharing process. } \\
\text { - A culture that emphasizad trust has been found to } \\
\text { help alleviate the negative effect of perceived } \\
\text { cost on sharing } \\
\text { - Aculture linked with Implementation of intranet- } \\
\text { based KMS, individual knowledge sharing, and } \\
\text { firm's capsbility of knowledge exchange and } \\
\text { combination } \\
\text { - Organization with cultures emphasizing } \\
\text { innovation are more likely to implement intranet } \\
\text { KMS }\end{array}$ \\
\hline Management Support & $\begin{array}{l}\text { King and Marks } \\
(2008)\end{array}$ & $\begin{array}{l}\text { They failed to find significant effect for perceived } \\
\text { organizational support after controlling for ease of } \\
\text { use and usefulness of KMS. }\end{array}$ \\
\hline $\begin{array}{c}\text { Reward and } \\
\text { incentives }\end{array}$ & $\begin{array}{l}\text { Kankanhali et al } \\
\text { (2005) } \\
\text { Cabrera et al (2006) } \\
\text { Kulkarmi et al(2006) } \\
\text { Block \& Kim (2002) } \\
\text { Block et al (2005) } \\
\text { Kwok \& Gao (2005) } \\
\text { Lin (2007) }\end{array}$ & $\begin{array}{l}\text { Rewards, such as promotion, bonus, and higher } \\
\text { salary have been shown to be positively related to } \\
\text { the frequency of knowledge contribution made to } \\
\text { KMS especially when employees identify with } \\
\text { organization } \\
\text { - Employe who received a higher level of } \\
\text { intensives to share and use knowledge are more } \\
\text { likely to report KM is useful } \\
\text { - Contrary, some researcher found that anticipated } \\
\text { extrinsic rewards had negative effect on attitudes } \\
\text { toward knowledge sharing }\end{array}$ \\
\hline $\begin{array}{c}\text { Organizational } \\
\text { Structure }\end{array}$ & $\begin{array}{l}\text { Liebowitz (2003) } \\
\text { Leibowitz \& } \\
\text { Megbolugbe (2003) } \\
\text { Yang \& Chen (2007) }\end{array}$ & $\begin{array}{l}\text { - In General results of the studies suggest that } \\
\text { organization should create doppotinitites for } \\
\text { employee interactions to occur and employee } \\
\text { rank, position in the organizational hierarchy, and } \\
\text { seniority should be deemphasized to facilitate } \\
\text { knowledge sharing. }\end{array}$ \\
\hline
\end{tabular}

Scholars have been identified factors contribute to KS success as described in Tables 1-4. The Factors consist of: organizational context, interpersonal and team, Individual and cultural characteristic and motivational factors. Factors contribute in organizational context are describes in table 1 are: organizational culture and climate, management support, reward and incentives and organizational factors.

TABLE II

FACTORS CONTRIBUTE IN KS FROM INTERPERSONAL AND TEAM CHARACTERISTIC

\begin{tabular}{|c|c|c|}
\hline Focus & Researcher & Result \\
\hline $\begin{array}{l}\text { Team characteristic } \\
\text { and processes }\end{array}$ & $\begin{array}{l}\text { Balkker et al (2006) } \\
\text { Sawng, Kim \& Han } \\
(2006)\end{array}$ & $\begin{array}{l}\text { - The result of studies suggest that team } \\
\text { characteristics and processes influence knowledgr } \\
\text { sharing among team members (e.g. } \\
\text { communication style, agreeable, and extravert } \\
\text { style) }\end{array}$ \\
\hline Diversity & $\begin{array}{l}\text { Sawng, et al (2006) } \\
\text { Philips, Mannix, } \\
\text { Neale, \& Gruenfeld } \\
\text { (2004) } \\
\text { Larson \& Harmon } \\
\text { (2007) }\end{array}$ & $\begin{array}{l}\text { Res earch has investigated how minority status of team } \\
\text { members relates to knowledge sharing. Minority base } \\
\text { on gender, martial status, or education were less likely } \\
\text { to share knowledge with team members. }\end{array}$ \\
\hline Social Network & $\begin{array}{l}\text { Chiu at al (2006), } \\
\text { Wasko and Faraj } \\
(2005) \\
\text { Kankanhalli, et } \\
\text { al(2005) } \\
\text { Nahapiet \& Ghosal } \\
(1998)\end{array}$ & $\begin{array}{l}\text { - In virtual communities both the number of direct } \\
\text { ties and pers onal relationships an individual has } \\
\text { with other members have been shown to be } \\
\text { positively related to quantity and perceived } \\
\text { helpfulnes s of knowledge share } \\
\text { - Existence of network connections and as sociated } \\
\text { social capital can facilitate knowledge sharing } \\
\text { within community of practice }\end{array}$ \\
\hline
\end{tabular}

TABLE III

FACTORS CONTRIBUTE IN KS FROM INDIVIDUAL AND CULTURAL CHARACTERISTIC

\begin{tabular}{|c|c|c|}
\hline Focus & Researcher & Result \\
\hline $\begin{array}{c}\text { Cultural } \\
\text { characteristic }\end{array}$ & $\begin{array}{l}\text { Ford \& Chan (2003); } \\
\text { Minbaeva (2007); } \\
\text { Hwang and Kim } \\
\text { (2007) }\end{array}$ & $\begin{array}{l}\text { National cultures and language } \\
\text { knowledge sharing }\end{array}$ \\
\hline $\begin{array}{c}\text { Individual } \\
\text { characteristic }\end{array}$ & $\begin{array}{l}\text { Constants et al (1996) } \\
\text { Wasko \& Faraj (2005) } \\
\text { Cabrera et al(2006) } \\
\text { Lin (2007) } \\
\text { Constant et al (1994) } \\
\text { Cabrera et al(2006) } \\
\text { Lin (2007) }\end{array}$ & $\begin{array}{l}\text { - Individual with higher expertise were more likely } \\
\text { to share useful knowledge when other employees } \\
\text { asked question using KMS } \\
\text { - Did not find individuals self rated expertise to be } \\
\text { related to knowledge sharing } \\
\text { - Individual who are more confident in their ability } \\
\text { to share their knowledge are morelikely to } \\
\text { express intentions to share knowledge } \\
\text { - Openness, ability to use computer, higher level } \\
\text { education have positive attitude toward } \\
\text { knowledge sharing }\end{array}$ \\
\hline
\end{tabular}

Team characteristic and process, diversity and social networks are important factors influences people in KS, as describe in table 2.

Researchers believe culture is the main drive for $\mathrm{KM}$ success; some factors related to culture are cultural characteristics and individual characteristic. Factors in cultural and individual are described in table 3.

Developing a culture and environment that support knowledge sharing is challenging for an organization. KS is a complex situation. Scholars consider using various theories of management, sociology, psychology and others have been applied to that problem. Factors that believe can encourage people involve in $\mathrm{KS}$ culture is motivational factors such as belief of knowledge ownership, perceived benefits and cost of KS, interpersonal trust and justice, and individual attitudes as described in table 4.

From studies conducted in perceived benefit and cost shows, benefits are positively associated with KS while perceived cots and time has negative influences. More benefit gets from KS would encourage people to do so.

TABLE IV

MOTIVATIONAL FACTORS CONTRIBUTE IN KS

\begin{tabular}{|c|c|c|}
\hline Focus & Researcher & Result \\
\hline $\begin{array}{l}\text { Beliefs of Knowledge } \\
\text { ownership }\end{array}$ & $\begin{array}{l}\text { Constant, et al (1994); } \\
\text { Kolekofsi \& } \\
\text { Heminger (2003) } \\
\text { Constant et al (1994); } \\
\text { Jarvenpas \& Staples } \\
(2000)\end{array}$ & $\begin{array}{l}\text { - Only a few studies have considered individuals' } \\
\text { believe regarding knowledge ownership } \\
\text { (organization or employees own knowledge) } \\
\text { - Research has shown that when employees } \\
\text { beliaved they owned information (rather than } \\
\text { organization) they were more likely to report that } \\
\text { they would engage in knowled ge sharing. }\end{array}$ \\
\hline $\begin{array}{l}\text { Perceived bene } \\
\text { costs }\end{array}$ & $\begin{array}{l}\text { Lin (2007); Hew \& } \\
\text { Hara (2007); Wasko \& } \\
\text { Faraj }(2000,2005) \\
\text { Bordia,et al (2006) }\end{array}$ & $\begin{array}{l}\text { Research shows that perceived benefits are } \\
\text { positively as sociated with knowledge sharing } \\
\text { while perceived cost have negative influences. } \\
\text { - Participating in knowledge sharing in online } \\
\text { community of practices has been found related to } \\
\text { increased internal satisfaction, perceived } \\
\text { obligation reciprocate the knowledge gain from } \\
\text { forum, enhanced professional reputations, and } \\
\text { helping advance the community Positive } \\
\text { influence of benefits on knowledge sharing only } \\
\text { for technology-aided sharing but not in a face-to- } \\
\text { face context. } \\
\text { The more time and effort employees perceived as } \\
\text { necessary to codify knowledge in order to share } \\
\text { knowledge the less likely they would use } \\
\text { electronic repositories for knowledge sharing } \\
\text { especially when there was a weak trust of other } \\
\text { employees contributing and reusing knowledge. }\end{array}$ \\
\hline $\begin{array}{l}\text { Interpersonal trust } \\
\text { and justice }\end{array}$ & $\begin{array}{l}\text { Wu, Hsu \& Yeh } \\
(2007)\end{array}$ & $\begin{array}{l}\text { - Trust and justice is important becaus e knowledge } \\
\text { sharing involving providing knowledge to another } \\
\text { pers on person or a collective such as team or } \\
\text { community of practices with expectation for } \\
\text { reciprocity }\end{array}$ \\
\hline Individual attitudes & $\begin{array}{l}\text { Bock \& } \operatorname{Kim}(2002) \\
\text { Ryu, Ho, \& Han } \\
(2003) \\
\text { Lin \& Lee (2004) }\end{array}$ & $\begin{array}{l}\text { - Individual expectations of usefulness of their } \\
\text { knowledge sharing and that through sharing they } \\
\text { can improve relationships with others have been } \\
\text { shown to be related to positive knowledge } \\
\text { sharing attitudes which in turn were related to } \\
\text { knowledge sharing intentions and behaviors }\end{array}$ \\
\hline
\end{tabular}




\section{Knowledge Management System}

In common, knowledge management systems (KMS) are IT that enables organizations to manage effective and efficient knowledge. Alavi and Leidner [1] defined KMS as a class of information systems applied for managing organizational knowledge. In general KMS would not have many differences from other information systems, instead of content and activities by users [1].

Another perspective of KMS comes from Ericsson and advic [8]. They defined KMS as a system that increase organizational performance by increase the better decision by employee when they use knowledge in daily work activities [8].

\section{Knowledge Management System Acceptance}

User technology acceptance model has contributed to our understanding of user technology acceptance factors and their relationship. Money and Turner [13] conducted study and found preliminary evidence that previous information technology acceptance research base on the Technology acceptance model (TAM), may serve as a foundation for research of knowledge Management system user acceptance [13].

However TAM also has limitations, Sun and Zhang [14] identified there are two limitations of TAM: the relatively low explanatory power and inconsistent influences of the factors across studies. They suggested that moderating factors may account for both limited explanatory power and the inconsistencies between studies, the nature of the task and the nature of the technology both can use as moderating factors affect the user in technology acceptance. A systematic examination of significant moderating factors should contribute to better understanding of the dynamic of the users technology acceptance [14].

In addition TAM has been widely use to examine KMS user acceptance, and proved can use to understand user behavior in KMS acceptance $[5,8,13,16]$. Most of researchers found that Perceived usefulness is the most influences factors in user KMS Acceptance. The researchers had integrated TAM with other theories to improve TAM power to explore user behavior in KMS acceptance. The theories that usually use are TRA, SCT, SNT, DOI, SET, etc.

$\mathrm{Xu}$ and Quaddus was proposed KMS acceptance model [16]. Figure 1 shows the model. The model developed by innovation stage model built on Rogers' in 1995 and with two most widely apply theory from Ajzen and Fishbein's, theory of reasoned action (TRA) and Davis, technology acceptance model. We use this model as a basis and propose the modified model. Our reason to use this model because the model in considering most important factors in KMS acceptance.

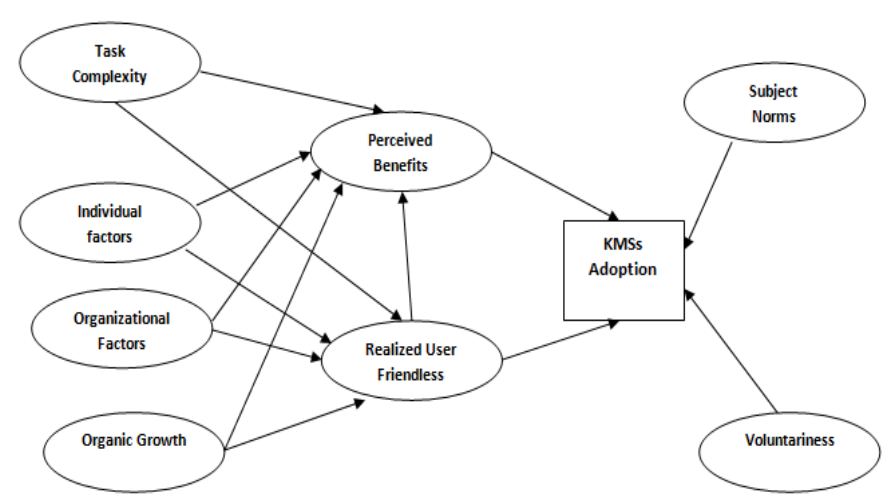

Figure 1. KMS pre-adoption acceptance mode (Xu and Quaddus, 2007)

\section{E. Gap in KMS Acceptance Research}

Knowledge workers as users in a knowledge management initiative can be categories as knowledge contributor and knowledge seeker. Nevertheless, very little research has been done on KMS user acceptance in both Prespertive of knowledge workers. Most of the KMS acceptance research has done studies in general perspective.

As state above, it is expected that understand both knowledge worker behaviors in the use of KMS in KM initiative is critical. The ability to identify, predict and manage both knowledge workers of KMS will facilitate implementation efforts, as acceptance of KMS by knowledge workers necessary for its ultimate success.

\section{DISCUSSION}

He and Wei [9] conducted a study of continued knowledge sharing. They proposed that KMS user's belief are contextually differentiated, and thus a distinction between knowledge contributor and knowledge seeker behavior. They argued that perceived usefulness not always mean to improved work performance, because if we view from the knowledge contributor perspective it will be different view [9].

He and Wei [9] proposed new understanding about perceived usefulness, they come with question "Does perceived usefulness always mean improved work performance?" If the answer is no for knowledge contributor circumstances, what are the factors we should adopt to predict the continue usage intention of knowledge contributor?

In this study we argue that perceived usefulness should be considered another value instead of work performance, because the effect on use KMS is not only in work performance but also in a wider environment such as culture in an organization or an image to be recognized for social status in group [7]. We propose another construct for perceived usefulness that named social, economic and psychological value as shows at fig. 2. 


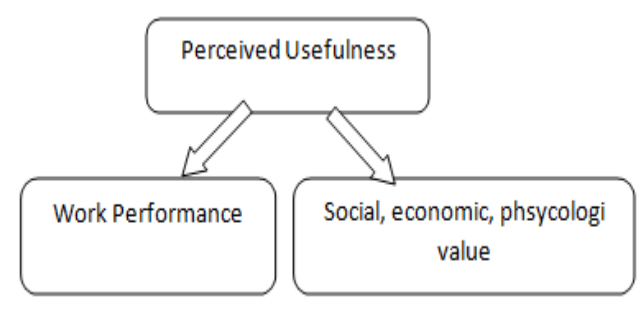

Figure 2. Propose new perspective of Perceived Usefulness

TABLE V

FACTORS IN WORKS PERFORMANCE AND SOCIAL, ECONOMIC, AND PHSYCOLOGICAL

\begin{tabular}{|c|c|}
\hline Work Performance & $\begin{array}{l}\text { Social, economic and } \\
\text { physiological value }\end{array}$ \\
\hline $\begin{array}{l}\text { - } \text { Creativity } \\
\text { - } \text { Productivity } \\
\text { - Cost and time reduction } \\
\text { - Knowledge building } \\
\text { - } \text { Avoiding same mistake } \\
\text { - Effectiveness }\end{array}$ & $\begin{array}{l}\text { - Enjoy helping } \\
\text { - Reciprocity } \\
\text { - Image } \\
\text { - Organizational rewards } \\
\text { - }\end{array}$ \\
\hline
\end{tabular}

Table 5 shows us element of work performance consist of creativity, productivity, cost and time reduction, knowledge building and avoid mistakes. In our belief impact of KS is not only about work performance, we belief that KS also impact in cultural, social, economy and psychological element. When people in the organization do KS the benefit can or they expectation can be enjoy helping, image or organization reward. The activities of KS also impact the social norm as reciprocity, people believe when she/he do $\mathrm{KS}$, in another time someone would do KS as well as she/he do.

It is important for us understand the role of people/employee as actors in KS. An employee who works in organization that implement $\mathrm{KM}$ recognize as a knowledge worker, knowledge worker who contribute their experiences to communities known as knowledge contributor, on the other hand knowledge worker who use or reuse the organization knowledge known as knowledge seeker. People who as act as knowledge contributor have special characteristic. They usually have good motivation to help others, and expert in one area.

The employee would not share what they know to other people in communities if they did not understand the benefit of doing so, or because they did not have enough time and effort to share their experiences [4]. Knowledge contributor is believed about image, enjoyment helping and reciprocity as a benefit of doing knowledge sharing. This study gives us opportunity to come up with an idea how to understand knowledge contributor and knowledge seeker belief from their own perspectives.

TABLE VI: KNOWLEDGE CONTRIBUTOR AND SEEKER BELIEF IN KS

Knowledge Seeker

- Creativity

- Productivity

- Cost and time reduction

- Knowledge building

- Avoiding same mistake

- Effectiveness

- Organizational rewards
TABLE VII KNOWLEDGE CONTRIBUTOR AND SEEKER HABIT

\begin{tabular}{|c|c|}
\hline Knowledge Contributor & Knowledge Seeker \\
\hline $\begin{array}{l}\text { - Have good motivation } \\
\text { to help } \\
\text { - Have good motivation } \\
\text { to sharing knowledge }\end{array}$ & $\begin{array}{l}\text { - Have a good motivation to } \\
\text { leam something new } \\
\text { - Hve a good motivation in } \\
\text { explore hew method and } \\
\text { procedure }\end{array}$ \\
\hline
\end{tabular}

As well as knowledge contributor knowledge seeker also have unique characteristic/habits in $\mathrm{KM}$ activities. Table 7 describes the habits from the seeker and contributor. Knowledge seekers have habits such as good motivation to learn something new, good motivation in exploring the new method / procedure. Some knowledge seeker barriers are they don't have time to doing it, too busy to finish job in office, and they did not get support from organization to explore the new method or procedure [4].

\section{SOLUTION}

Outcome from literature review has shown that most of the current KMS acceptance models focus only on knowledge seeker perspective. There is a need a KMS model that takes into account not only knowledge seeker but also knowledge contributor. Thus, this study will propose an enhanced model of the KMS acceptance model to solve the problem. This model incorporates both perspectives of knowledge worker, we believe this model can be used to examine and understand the knowledge worker behavior of KMS acceptance.

The original KMS acceptance model as suggested by Jun and Quaddus has been divided into two separate models [16] First model is used to understand knowledge seeker, and the other one is used to understand contributor behavior as described in figure 3. Second model can use to understand seeker behavior as shown in figure 4.

The researcher proposes to the richness scope of perceived of usefulness, and consider perceived usefulness not only about task performance but also about social, economical and psychological impact as we discuss in the previous section. We propose a new explanation about perceived usefulness / benefits for seeker and contributor and new user friendless for seeker and contributor.

Elements consider for seeker in this model consist of:

- Seeker Realized User Friendliness--This constructs of perceived user friendliness reflect the perspectives of end-user focus on the KMSs and is made up of simple to learn and use, cheap to learn and use, speed, accessibility, quality of knowledge, security, complexity, and risk of knowledge

- Seeker Realized User Friendliness--This constructs of perceived user friendliness reflect the perspectives of end-user focus on the KMSs and is made up of simple and cheap to use, speed, accessibility, security, and risk of knowledge. 


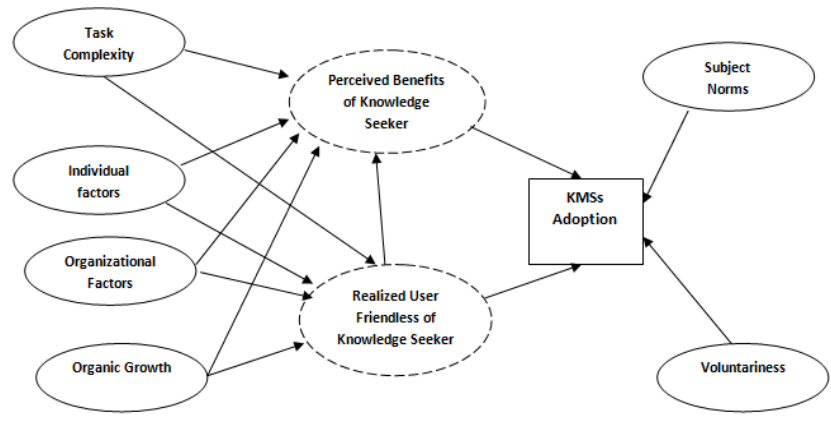

Figure 3: KMS Acceptance model (knowledge seeker perspectives).

Element considers both (Seeker and contributor):

- Continued Used of KMSs--The construct of continued use of KMSs is represented by future uses of KMSs in the areas of knowledge and expert information search; communication with knowledge holders; knowledge sharing; contribution to the system; codifying and storing knowledge; knowledge creation; and KMS habit

- Perceived Voluntariness--Perceived voluntariness is the degree to which the use of KMSs is perceived as being voluntary, or free will. The construct of perceived voluntariness is reflected in three dimensions: (1) voluntary use, (2) superior request, and (3) job description

- Subject Norm--Subject norms refer to the person's perception that most people who are important to him/her thinks he/she should or should not use KMSs to perform a task. End users' use of KMS can be influenced by others, such as leader, peers, respected people, superiors and subordinates.

- Organizational Factors--Organizational factors in the proposed research model are represented by organizational structure, organizational culture, IT infrastructure, business processes, IT/IS department, and top management support

- Task Complexity Factors--Task complexity factors consist of multidisciplinary project, overload knowledge, and effective knowledge reuse.

- Organic Growth factors--The concept of organic growth is made of three factors: (1) enticement and education, (2) training and (3) individual learning

Element consider for Contributor:

- Contributor Perceived Benefits--This constructs are presented by six dimensions of potential benefit and driving forces of KMSs. The five dimensions are: (1) reciprocity, (2) altruism, (3) incentive, (4) reputation (5) enjoy helping

- Contributor Realized User Friendliness--This constructs of perceived user friendliness reflect the perspectives of end-user focus on the KMSs and is made up of simple and cheap to use, speed, accessibility, security, risk of knowledge, perceive of Knowledge ownership.

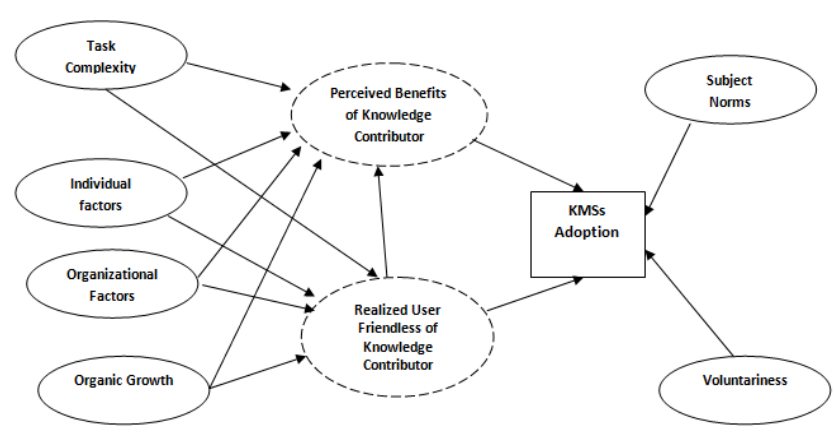

Fig.4. KMS Acceptance model (knowledge contributor perspectives)

\section{CONCLUSION AND FUTURE WORK}

This paper enhanced KMS acceptance model from $\mathrm{Xu}$ and Quaddus [16] by integrating two different perspectives of knowledge worker. The perspective was based on their different belief in KS benefit. This is because in the end individual will use KMS if they receive the benefit from their activities. The decision whether the user will use or not the KMS is based on their willingness to share their knowledge. The further work is to develop KMS acceptance model, and test the model in real practices.

\section{ACKNOWLEDGMENT}

The authors wish to thank to the reviewers for their constructive comments. We also would like to thanks to Universiti Teknologi Malaysia for supporting this work.

\section{REFERENCES}

[1] M. Alavi and D. E. Leidner, "Review: Knowledge Management and Knowledge Management Systems Conceptual Foundations and Research Issues," MIS Quarterly vol. 25(1), pp. 107-136, 2001.

[2] K. M. Bartol and A. Srivastava, "Encouraging Knowledge Sharing: The Role of Organizational Reward Systems," Journal of Leadership \& Organizational Studies, vol. 9, pp. 64-76, Summer 20022002.

[3] G. D. Bhatt, "Knowledge management in organizations: examining the interaction between technologies, techniques, and people," Journal of Knowledge Management, vol. Vol. 5 pp. pp. $68-75,2001$.

[4] A. Cabrera and E. F. Cabrera, "Knowledge-Sharing Dilemmas," Organization Studies, vol. 23, pp. 687-710, September 1, 20022002.

[5] P. F. Clay, et al., "Factors Affecting the Loyal Use of Knowledge Management Systems," in System Sciences, 2005. HICSS '05. Proceedings of the 38th Annual Hawaii International Conference on, 2005, pp. 251c-251c.

[6] F. D. Davis, et al., "User Acceptance of Computer Technology: A Comparison of Two Theoretical Models," Management Science, vol. 35, pp. 982-1003, 1989.

[7] A. R. Dennis and B. A. Reinicke, "Beta versus VHS and the Acceptance of Electronic Brainstorming Technology," MIS Quarterly, vol. 28, pp. 1-20, 2004.

[8] F. Ericsson, \& Avdic, A, "Knowledge Management Systems Acceptance," In E. Coakes (Ed.), Knowledge Management: Current Issues and Challenges, pp. (pp. 39-51), (2003).

[9] W. He and K.-K. Wei, "What drives continued knowledge sharing? An investigation of knowledge-contribution and - 
seeking beliefs," Decision Support Systems, vol. 46, pp. 826838, 2009.

[10] A. Kankanhalli, et al., "Contributing Knowledge to Electronic Knowledge Repositories: An Empirical Investigation," MIS Quarterly, vol. 29, pp. 113-143, 2005.

[11] U. R. Kulkarni, et al., "A Knowledge Management Succes Model : Theoritical Development and Empirical Validation," Journal of Management Information Systems, vol. 23. No.3, pp. 309-347, 2006

[12] R. Maier, "Information and Communication Technologies for Knowledge Management." vol. 3rd ed, ed, 2007, p. 125 illus.

[13] W. Money and A. Turner, "Assessing knowledge management system user acceptance with the Technology Acceptance Model," International Journal of Knowledge Management, vol. 1 pp. 8-26 2008.

[14] H. Sun, and P. Zhang "'Applying Markus and Robey's Causal Structure to Examine User Technology Acceptance Research: A New Approach"," Journal of Information Technology Theory and Application (JITTA) vol. 8:2 pp. 2140., 2006.

[15] M. M. Wasko and S. Faraj, "Why Should I Share? Examining Social Capital and Knowledge Contribution in Electronic Networks of Practice," MIS Quarterly, vol. 29, pp. 35-57, 2005.

[16] J. Xu, \& Quaddus, M "Exploring the Factors Influencing End Users' Acceptance of Knowledge Management Systems: Development of a Research Model of Adoption and Continued Use," Journal of Organizational and End User Computing (JOEUC), vol. 19(4), pp. 57-79, (2007).

\section{BIOGRAPHIES}

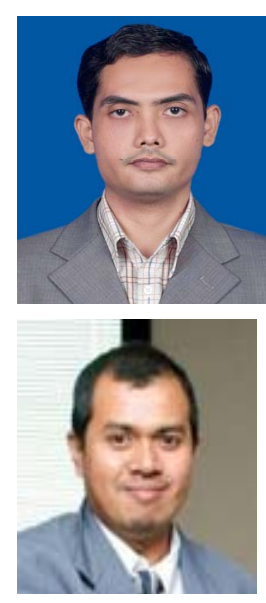

Setiawan Assegaff was born in Tanjung Karang, Indonesia, on May 23, 1978. He graduated from the Gunadarma University, Indonesia, and now as $\mathrm{PhD}$ student at the Universiti Teknologi Malaysia, Malaysia. His special fields of interest included Knowledge Management, Technology Adoption and Computer and Society.

Ab Razak Che Hussin was born in Malaysia on September 9, 1973. He graduated from the University of Manchester, UK in 2006 after completed his PhD in Trust in e-Commerce. He is now senior lecturer at Universiti Teknologi Malaysia, Malaysia. His special fields of interest included Information System, Web Application, and Trust and Privacy in e-Commerce. For further information please visit http://www.is.fsksm.utm.my/razak/

Halina Mohamed Dahlan was born in

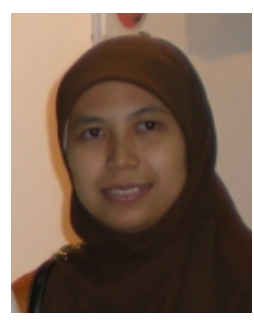
Malaysia on November 1974. She graduated from the University of Manchester UK in 2008 after completing her $\mathrm{PhD}$ in Intelligent Decision Support Systems. She is now senior lecturer at Universiti Teknologi Malaysia, Malaysia. Her special fields of interest included business intelligent, evolutionary computing, and fuzzy logic. For further information please visit http://www.is.fsksm.utm.my/halina/ 